\title{
Why pledges alone will not get plastics recycled - Comparing recyclate production and anticipated demand
}

\section{Sebastian Kahlert ( $\nabla$ skahlert@ethz.ch )}

ETH Zurich https://orcid.org/0000-0002-4894-1876

\section{Catharina Bening}

Swiss Federal Institute of Technology Zurich (ETHZ)

\section{Article}

Keywords: polyethylene terephthalate, recycling, pledged volume

Posted Date: November 8th, 2021

DOI: https://doi.org/10.21203/rs.3.rs-99379/v1

License: (c) (i) This work is licensed under a Creative Commons Attribution 4.0 International License.

Read Full License

Version of Record: A version of this preprint was published at Resources, Conservation and Recycling on June 1st, 2022. See the published version at https://doi.org/10.1016/j.resconrec.2022.106279. 


\section{Why pledges alone will not get plastics recycled - Comparing recyclate production and anticipated demand}

Plastics are a versatile material, but environmental concerns exist with regard to its usage and disposal. Only $9 \%$ of the roughly $8.3 \mathrm{bn}$ metric tons produced since the 1950 s have been recycled and $12 \%$ incinerated, sending the vast majority of it to (often unmanaged) landfill ${ }^{1}$. Publications such as the Branded report have drawn the public's attention to the downsides of global plastics consumption ${ }^{2}$ and respective policies are put in place at an unprecedented speed. The environmental damage of disposed plastics to the world's marine ecosystems was calculated at 13bn USD per year ${ }^{3}$. Nevertheless, the world's plastic production is growing from year to year, standing at $359 \mathrm{~m}$ tons in $2018^{4}$ and is expected to pass the $1 \mathrm{bn}$ mark before 2050 . This could lead to a rising share of plastics' total oil consumption from $6 \%$ today to $20 \%$ by 2050 , equivalent to $15 \%$ of the carbon budget in a $2{ }^{\circ} \mathrm{C}$ scenario ${ }^{5}$. Hence, plastics are also playing a vital role with regard to net zero emissions goals and the mitigation of climate change $\mathrm{e}^{6,7}$.

Under rising public scrutiny and political ambitions (e.g., the EU's single-use plastics directives), brand owners - being the face of plastic packaging - have pledged to reduce their consumption of virgin material and use more recycled contents. In light of this development, two major voluntary pledging campaigns have been started in 2018:

- The Ellen MacArthur Foundation and the UN Environment Programme initiated the New Plastics Economy Global Commitment in October 2018, uniting over 450 businesses (i.e. brand owners, packaging companies, recyclers, etc.), governments and other organizations from around the world behind a common vision and set of 2025 targets. Those include, among others, moving from singleuse to multiple use, ensuring $100 \%$ of plastic packaging to be reusable, recyclable or compostable, and setting ambitious recycled content targets between $25-100 \%$ across all packaging used for brand owners and packaging companies ${ }^{8}$.

- The European Commission launched the Circular Plastics Alliance in December 2018 "to boost the EU [European Union] market for recycled plastics"9. According to the latest report of March 2019, 70 companies along the whole value chain have submitted their pledges, including major organizations such as Petcore Europe, Vinylplus and European Plastics Converters. In line with the European Strategy for Plastics in the Circular Economy, the Alliance wants to collect pledges amounting to $10 \mathrm{~m}$ tons of recycled plastics per year finding their way into products within the EU by 2025 . With a demand of European converters of $51.2 \mathrm{~m}$ tons in 2018 , this would be roughly $20 \%$ of the total EU plastics volume ${ }^{9}$.

Despite these ambitious actions, there is reason for caution as previous pledges in this field have not been fulfilled: In 1990, Coca Cola pledged to use 25\% recycled content in its bottles by 2015 - the same goal as now announced for 2025 - while currently only $10 \%$ have been realized ${ }^{10}$. PepsiCo and Nestlé have failed similarly, exhibiting the limited effectiveness of pledges alone. Even more so, as recyclate in sufficient quality for (food) packaging applications remains to be scarce. The (recycling) industry has developed since but the fragmented nature of the market still impairs comprehensive and transparent assessment.

In this paper, we analyze the current flow of Polyethylene Terephthalate (PET) in the EU from production to recycling and compare it to the pledged consumption of its recyclate (rPET) five years from now. We find a significant gap to fulfillment, discuss potential developments and roadblocks along the way and formulate three scenarios that may have a decisive influence on the way forward.

We are focusing on PET for two reasons: First, it is one of the most-widely used materials in food packaging, which is the key area for many pledges and regulatory targets. In fact, it makes up $21 \%$ of all plastic packaging demand in Europe ${ }^{4,11}$, mostly in the form of bottles or trays. However, due to its short usage, it is also among the most littered types of plastic ${ }^{2}$. Second, PET can be recycled in a closed loop manner - e.g., bottle to bottle recycling - and is available in market quantities, due to high collection rates driven by deposit return schemes (DRS) and the availability of large sorting and recycling capacities. 
We have calculated the pledged rPET volumes for the $\mathrm{EU}^{*}$, since it has one of the highest consumption rates of plastic packaging worldwide. For this reason, it has developed the most advanced regulatory framework and infrastructure for polymer recycling. This comes with good data availability as well as a separate pledging scheme, allowing for a comprehensive analysis.

Fig. 1: PET production and recycling in Europe 2018 vs. pledges for 202511-13

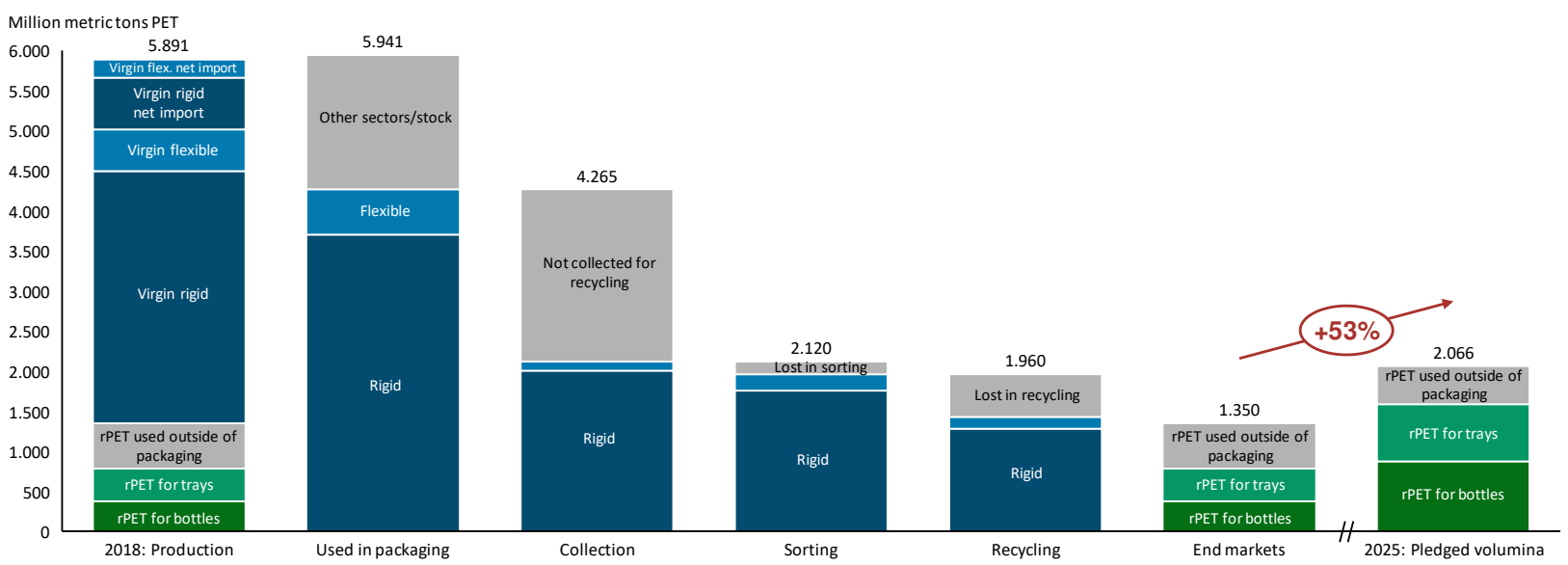

We have built and evaluated an extensive database of companies and material flows along the entire value chain of PET, including production and recycling data in Europe, the relevant imports and exports as well as the pledges from the above mentioned campaigns (see Figure 1). We not only draw from different existing databases (e.g., Eurostat) and information in industry and company reports (e.g., Petcore), but also corroborated and complemented our findings in interviews with company representatives along the value chain.

In 2018, roughly $4.3 \mathrm{~m}$ of the $5.9 \mathrm{~m}$ tons of PET placed on the market were used in packaging ${ }^{11,12}$, with the major share of it being rigid material (e.g., for bottles, while flexible is used in trays/films). Only 50\% were collected for recycling, with the rest being incinerated in mixed waste streams or landfilled. After deducting the losses in sorting and recycling, 1.35m tons of rPET in different qualities were produced in 2018 (see Figure 1: End markets).

In contrast, the pledged volume for the year 2025 amounts to $2.066 \mathrm{~m}$ tons ${ }^{9}$. To reach this goal, the output of rPET will have to increase by 53\% over the coming five years. This is challenging for at least three reasons: First, the overall quantity is going to be difficult to achieve, especially when looking at the comparatively low annual growth of collection and recycling volumes of $3.6 \%$ and $1.9 \%$ since 2014 , respectively ${ }^{14}$. Second, not only does the recyclate have to be provided in sufficient quantity, but the quality of the material also has to fit the purpose, with packaging for food exhibiting higher requirements than for any other packaging application. Third, other industries compete for rPET as well: 68\% of the recyclate in 2018 was used in different end markets such as non-food packaging (26\%), fibres (24\%), strapping (10\%) and others (8\%) ${ }^{11}$. Those markets can oftentimes pay much higher prices since e.g., margins are higher on clothing than on water bottles - and they can take in the lower quality recyclate. Hence, the pledges made have to be self-reinforcing and should ideally unfold substantial investments - or trigger regulatory interventions - to reach the self-imposed goal. These investments to help turn the tide must occur on all steps of the value chain: in collection, sorting and recycling.

\section{Collection}

Overall, the collection rates of post-consumer plastic packaging waste are slowly increasing at $2.25 \%$ p.a. from $14.9 \mathrm{~m}$ tons in 2006 to $17.8 \mathrm{~m}$ tons in $2018^{4}$. However, the approaches to collection differ by country, with some going for mixed collection together with other recyclables such as paper, cardboard or aluminum (e.g., Belgium, France, Italy) versus others preferring separate material streams (e.g., Austria, Netherlands, Denmark) ${ }^{15}$. Furthermore, currently only 8 of the 27 EU member states have a mandatory deposit return scheme for PET bottles, while five more are planning on introducing it over the next years. Comparing the

* The production data is based on EU28 data from Eurostat, whereas the market, collection, sorting and recycling data is based on the EU28 plus Norway and Switzerland. 
collection rates from countries with a deposit return scheme (87.7\%) to those without it (46.5\%), there is a significant potential for increasing bottle collection volumes through this measure ${ }^{11,16}$. Generally, the current recycling quota of around $31.4 \%{ }^{*}$ could be significantly enlarged if durable goods outside of packaging were collected as well.

Sorting

Currently, the European Food Safety Agency allows for only 5\% of recycling inputs to come from non-food consumer applications if the resulting rPET should qualify for usage in food packaging ${ }^{17}$. This requires a separate sorting for PET food packaging, which is currently only available for PET bottles. A widely discussed relaxation of this threshold would allow for more rPET to be reused in food packaging. In addition, technological advances in digital watermarking and chemical tracing will improve the sorting process and reduce the losses at this step ${ }^{18}$.

\section{Recycling}

Since 2014, the European PET recycling industry has seen very little growth, with an installed capacity of $2.2 \mathrm{~m}$ tons input material in 2018 (incl. the United Kingdom, Norway and Iceland) ${ }^{11}$. Although a few new plants are scheduled to come into operation, the significant investments of $\sim € 1 \mathrm{~m}$ per kiloton of input material prevents a rapid capacity expansion. Improvements in collection and sorting would increase the recycling outputs, though, as most of the plants are not yet running at full utilization.

In face of the industry's pledge for $2.066 \mathrm{~m}$ tons of rPET used in 2025, we sketch three different scenarios that are expected to have a decisive influence on the gap between the current projection of rPET supply in 2025 and what has been promised. Specifically, we analyze how our findings change if

a. a DRS for bottles is introduced in selected countries and hence more bottles are collected;

b. a quota on re-use instead of single-use of bottles is introduced in a country like Germany;

c. the market for rPET applications is growing in areas that are not primarily catered with current rPET, replacing alternative materials, e.g., in the textiles industry.

Given these scenarios, we calculate the additional investments needed and discuss possible policy interventions that may help the restructuring of the rPET industry in different ways. Thereby, we sketch a trajectory to increase recycling quotas, helping brand owners to fulfill their pledges and reducing overall greenhouse gas emissions through recycling.

\section{References}

1. Geyer, R., Jambeck, J. R. \& Law, K. L. Production, use, and fate of all plastics ever made. Science advances 3, e1700782; 10.1126/sciadv.1700782 (2017).

2. Greenpeace. Branded: In search of the World's top corporate plastic polluters\} 1, 29 (2018).

3. Raynaud, J., Richens, J. \& Russell, A. Valuing plastic. The business case for measuring, managing and disclosing plastic use in the consumer goods industry / author, Julie Raynaud ; editor, James Richens, Andrew Russell (UNEP, Nairobi, Kenya, 2014).

4. PlasticsEurope. Plastics - the Facts 2019, 2019.

5. World Economic Forum, Ellen MacArthur Foundation \& McKinsey \& Company. The New Plastics Economy - Rethinking the future of plastics, 2016.

6. Zheng, J. \& Suh, S. Strategies to reduce the global carbon footprint of plastics. Nat. Clim. Chang. 9, 374-378; 10.1038/s41558-019-0459-z (2019).

7. IPCC. Global Warming of $1.5^{\circ} \mathrm{C}$. An IPCC Special Report on the impacts of global warming of $1.5^{\circ} \mathrm{C}$ above pre-industrial levels and related global greenhouse gas emission pathways, in the context of strengthening the global response to the threat of climate change, sustainable development, and efforts to eradicate poverty, 2014.

8. Ellen MacArthur Foundation. New Plastics Economy Global Commitment Signatories - October 2019, 2019.

${ }^{*}$ I.e. $1.35 \mathrm{~m}$ tons rPET divided by $4.3 \mathrm{~m}$ tons PET used in packaging in 2018. 
9. Assessment report of the voluntary pledges under Annex III of the European Strategy for Plastics in a Circular Economy. SWD(2019) 92 final (2019).

10. Friedman-Nathan, E. Talking Trash (2020).

11. Plastic Recyclers Europe, Petcore Europe \& EFBW. PET Market in Europe - State of Play, 2020.

12. Eurostat. Packaging waste statistics. Eurostat, 17 (2019).

13. PlasticsEurope. Plastics - the Facts 2018, 2018.

14. Petcore Europe. Growth of PET collection and recycling in Europe continues: over 1.8 million tonnes of PET bottles collected and recycled in 2015 (2016).

15. BiPRO \& CRI. Assessment of separate collection schemes in the 28 capitals of the EU. Final Report, 13.11.2015.

16. Alvarado Chacon, F., Brouwer, M. T. \& Thoden van Velzen\}, Eggo Ulphard. Effect of recycled content and rPET quality on the properties of PET bottles, part I: Optical and mechanical properties. Packaging Technology and Science, 1--11; 10.1002/pts.2490 (2020).

17. PET recycling processes for food contact materials: EFSA adopts first opinions (2012).

18. Belder, G. de. HolyGrail: tagging packaging for accurate sorting and high-quality recycling (2020). 